\title{
Comparing Antibacterial and Antioxidant Activity of Annatto Dye Extracted by Conventional and Ultrasound-Assisted Methods
}

\author{
Mahmoud Yolmeh ${ }^{1, *} ;$ Mohammad Bagher Habibi-Najafi ${ }^{2}$; Shahrzad Shakouri ${ }^{3}$; Fereshteh \\ Hosseini $^{4}$ \\ ${ }_{1}^{1}$ Faculty of Food Sciences and Technology, Gorgan University of Agriculture Sciences and Natural Resource, Gorgan, IR Iran \\ ${ }^{2}$ Department of Food Sciences and Technology, Faculty of Agriculture, Ferdowsi University of Mashhad, IR Iran \\ 3 Department of Food Sciences and Technology, Faculty of Sciences, Sabzevar Branch, Islamic Azad University, Sabzevar, IR Iran \\ ${ }^{4}$ Academic Center for Education, Culture and Research, Mashhad, IR Iran \\ *Corresponding author: Mahmoud Yolmeh, Faculty of Food Sciences and Technology, Gorgan University of Agriculture Sciences and Natural Resource, Gorgan, IR Iran. \\ E-mail: mahmud.yolmeh@yahoo.com
}

Received: March 3, 2014; Accepted: April 22, 2014

\begin{abstract}
Background: Annatto dye is used extensively in food industry that has antibacterial and antioxidant properties.
Objectives:Aim of this paper was comparison of the antibacterial and antioxidant properties of annatto dyewas extracted by conventional and ultrasound-assisted extraction (UAE) methods.

Materials and Methods: In this experimental study minimum inhibitory concentration (MIC) and minimum bactericidal concentration (MBC) of annatto dye against the bacteria were determined by agar dilution method. Antioxidant activity of annatto dye was evaluated by DPPH method.

Results: Gram-positive bacteria show more sensitivity to annatto dye than Gram-negative bacteria. Annatto dye extracted by UAE has more antibacterial and antioxidant activity compared to conventional method. Bacillus subtilis and Escherichia coli have the highest and the lowest sensitivity to annatto dye, respectively.

Conclusions: Annatto dye extracted by UAE showed a bactericidal effect against Salmonella enteritidis, however the dye extracted by conventional method the opposite is true.
\end{abstract}

Keywords: Annatto; Antibacterial; Antioxidant; Ultrasound-assisted

\section{Background}

Color is a constituent and is one of the first characteristics sensed by consumers. Simultaneous with the increasing awareness of toxicity of synthetic colors, need for colorants from natural sources has increased $[1,2]$. The natural colors that are often called biocolors, because of their biological source usually extracted from vegetables, fruits, roots, and microorganisms [3]. The annatto dye is a natural colorant comprised of carotenoids pigment that extracted from the pericarp of Bixaorellana L. seeds. Annatto creates orange to red color in foodstuffs and be used as a natural pigment in a variety of foods [4]. The major component of the annatto dye is $9^{\prime}$-cis-bixin that is soluble in oil and $9^{-}$-cis-norbixin is the major dye component of the alkaline extract that is soluble in water $[5,6]$. From economically point of view, annatto dye is the second natural additive color that is used in the world and demand for this color is increasing [7]. Giving the previous studies, annatto dye has antimicrobial and antioxidant activity. These characteristics are associated with the conjugated bonds in its structure [8]. Moreover, it has been documented that annatto dye can act as anti- cancer agent and destroy cancer cells [9].

Conventional techniques of color extraction such as maceration are very time-consuming and require relatively large quantities of solvents. Nowadays, novel extraction methods such as microwave assisted extraction, ultrasonic-assisted extraction (UAE), supercritical fluid extraction, enzymatic extraction have been developed for the extraction of active components from plants [10,11]. Advantage of medicinal plants by man has been known for centuries, and therapeutic benefit of several herbal species has been widely delineated and these plants might act as an alternative treatment of infectious diseases $[12,13]$. Giving the World Health Organization (WHO), medicinal plants would be the best source for acquiring variety of drugs [14]. These evidences give to support and quantify the importance of screening natural products.

\section{Objectives}

The aim of this study was comparison of the antibacterial and antioxidant properties of annatto dyes that extracted by conventional and UAE methods. 


\section{Materials and Methods}

In this experimental study annatto seeds were prepared from Hyderabad, India. All chemical materials were of analytical grade and purchased from Merck (Germany), Sigma-Aldrich (UK).

Conventional extraction: Color extraction from annatto seeds was done giving Castello et al. method with slight modification [15]. Based on this method, a certain amount of annatto seeds was soaked in n-hexane for 6 hours in order to remove oils. After filtration, the defatted seeds were used for dye extraction. Since chloroform showed the highest yield of extraction during preliminary experiments, this solvent was exploited for dye extraction. Temperature and extraction time were $48^{\circ} \mathrm{C}$ and 2 hours, respectively. The extract was filtered through Whatman filter paper NO.1 and then vacuumdried in the $1410 \mathrm{D}-2 \mathrm{E}$ vacuum oven (Shel Lab, USA) to produce the dye powder. Low temperatures $\left(40^{\circ} \mathrm{C}\right)$ were applied to prevent thermal dissociation of conjugated double bonds during drying.

Ultrasound-assisted extraction (UAE): Annatto seeds were defatted by soaking in n-hexane. The defatted seeds were placed in glass mixed with chloroform. UAE process performed in XL2020 modele's of ultrasonic device (20 $\mathrm{KHz}, 550 \mathrm{~W}$, Misonix, Germany). The working power, frequency, and extraction time were fixed at $200 \mathrm{~W}, 20 \mathrm{KHz}, 7$ minutes, respectively [16]. The dye powder was produced according to mentioned above method.

Microorganisms and culture media: Eight bacteria were tested in this study and include, Escherichia coli (ATCC 25922), Staphylococcus aureus (ATCC 25923), Bacillus cereus (ATCC 70876), Bacillus subtilis (donated by Department of Veterinary, Ferdowsi University of Mashhad), Streptococcus pyogenes (ATCC 19615), Enterococcus faecalis (ATCC 29212), Salmonella enteritidis (donated by Department of Veterinary, Ferdowsi University of Mashhad), Listeria innocua (ATCC 33090). All culture media were purchased from Merck (Germany). Microorganisms were grown overnight on trypticase soy broth (TSB), under optimal conditions. Overnight cultures were adjusted to match a 0.5 McFarland standard and further diluted 1:100 with Mueller-Hinton broth (MHB). The dilution obtained served as the inoculums for antibacterial activity assay.

Antibacterial activity assay: The disk agar diffusion method was done according to Galindo-Cuspinera et al. method [5]. The objective was to measure any halo of inhibition caused by a specific annatto dye solution. In practice, $0.10 \mathrm{~mL}$ of inoculums was spread with glass sticks onto Mueller-Hinton agar (MHA). Sterile $6 \mathrm{~mm}$ paper disks were soaked with concentrations of 0.5 , $1.5,2.5,3.5$ and $5 \mathrm{mg} / \mathrm{mL}$. Plates were stored at $37^{\circ} \mathrm{C}$ and the halo of inhibition was measured after $18-24$ hours of incubation. A disk containing knows amounts of penicillin or gentamicin was placed in plates as a comparative standard. A minimum of three replicates was performed for each bacterium.
Determination of minimum inhibitory concentration (MIC): Agar dilution method was used to determine MIC of bacteria. In practice, annatto dye in specific concentrations $(2,4,8,16,32$ and $64 \mathrm{mg} / \mathrm{mL})$ was mixed with sterile Mueller Hinton agar then $0.1 \mathrm{~mL}$ of bacterial suspension (0.5 McFarland) was plated as pour-plat. Plates were maintenance at $37^{\circ} \mathrm{C}$ and the MIC of bacteria was evaluated after 18 -24 hours of incubation [17]. The MIC was defined as the lowest concentration of annatto dye in a plate with no visible growth. A plate contain medium and without bacteria, and a plate include medium and bacteria was considered also as negative and positive control, respectively [17].

Determination of minimum bactericidal concentration (MBC): The agar dilution method was used also to determination of MBC. With this difference that microorganisms were sub-cultured in nutrient broth. If bacteria cannot grow in nutrient broth the MIC and MBC concentration will be equal. But in case of bacteria grow in nutrient broth, from the grown bacteria were sub-cultured in Mueller Hinton agar containing the further of annatto dye concentrations $(8,16,32,64$ and $128 \mathrm{mg} / \mathrm{mL})$ and the $\mathrm{MBC}$ considered as concentration of the dye that bacteria did not grow.

DPPH assay: Determination of antioxidant activity performed according to the method of Kurniawati et al. 1 $\mathrm{mL}$ of ASE dissolved in acetone was added to $4 \mathrm{~mL}$ of 0.1 mmol DPPH in a solution of $95 \%$ methanol. This solution was used as a blank. Absorbance at $517 \mathrm{~nm}$ was measured spectrophotometrically after 30 minutes incubation. The inhibition activity was calculated by the Equation 1 [18].

(1)

$$
\text { \%Inhibition }=\left[1-\left(\frac{\mathrm{Abs}_{\text {sample }}}{\mathrm{Abs}_{\text {control }}}\right)\right] \times 100
$$

Abs $_{\text {sample: }}$ absorbance value of sample

$\mathrm{Abs}_{\text {control }}$ : absorbance value of control

\section{Results}

Results disk agar diffusion: Tables 1 and 2 demonstrate the results of disk diffusion. Giving the results annatto dye has antibacterial effect on the all of examined bacteria. In both dye extraction method, B. subtilis and $E$. coli have the highest and the lowest sensitivity to annatto day.

Determination of MIC: Tables 3 and 4 show the MIC of annatto dye extracted by conventional and UAE methods, respectively, for the bacteria. According to the results annatto dye has inhibitory effect against the bacteria. Annatto dye was extracted by conventional method has the lowest MIC for B. cereus and B. subtilis with $16 \mathrm{mg} /$ $\mathrm{mL}$ and highest MIC for E. coli, S. enteritidis and E. faecalis with $64 \mathrm{mg} / \mathrm{mL}$. Giving to Table 4 annatto dye extracted by UAE method has the lowest MIC for B. cereus and $B$. subtilis $8 \mathrm{mg} / \mathrm{mL}$ and highest MIC for E. coli and S. enteritidis with $64 \mathrm{mg} / \mathrm{mL}$. 
Yolmeh $M$ et al.

Determination of MBC: The MBC of annatto dye for the bacteria are shown in Tables 5 and 6. Annatto dye extracted by conventional method has lowest MBC for $B$. cereus and B. subtilis (16 mg/mL). However, this dye has not bactericidal effect on $E$. coli and S. enteritidis. The dye extracted by UAE method has lowest $(8 \mathrm{mg} / \mathrm{mL})$ and highest (128 $\mathrm{mg} / \mathrm{mL}$ ) MBC for B. subtilis and S. enteritidis, respectively, but this dye has not bactericidal effect on E. coli.

Antioxidant assay: The result of DPPH assay showed that IC50 of annatto dye extracted by UAE was less than the dye extracted by conventional method. IC50 of the ASE extracted by UAE and the conventional extraction were 547.8 and $549.3 \mathrm{ppm}$, respectively (IC50 of $\beta$-Carotene was $552.1 \mathrm{ppm})$.

Table 1. Average Diameter (mm) of Microbial Free Zone Area of Annatto Dye Extracted by Conventional Method

\begin{tabular}{lcccccc}
\hline & $\mathbf{0 . 5}^{\mathrm{a}}$ & $\mathbf{1 . 5}^{\mathbf{a}}$ & $\mathbf{2 . 5}^{\mathbf{a}}$ & $\mathbf{3 . 5}^{\mathbf{a}}$ & $\mathbf{5}^{\mathbf{a}}$ & \multicolumn{2}{c}{ Antibiotic Disk $^{\mathrm{b}}$} \\
\hline Bacillus cereus & 8.4 & 9.4 & 11.4 & 12.2 & 12.7 & $13 \mathrm{P}$ \\
Escherichia coli & 7.6 & 8.1 & 8.5 & 9.4 & 10.4 & $12 \mathrm{G}$ \\
\hline Staphylococcus aureus & 7.9 & 8.5 & 9.8 & 10.8 & 11.4 & $32 \mathrm{P}$ \\
Salmonella enteritidis & 6.7 & 7.9 & 8.8 & 10.6 & 11.1 & $10 \mathrm{G}$ \\
\hline Listeria innocua & 8.1 & 9 & 9.8 & 11.2 & 12.2 & $22 \mathrm{P}$ \\
Bacillus subtilis & 8.6 & 9.7 & 11.8 & 13.1 & 13.5 & $14 \mathrm{P}$ \\
Streptococcus pyogenes & 8.3 & 9.5 & 10.9 & 12.1 & 12.8 & $13.5 \mathrm{P}$ \\
Enterococcus faecalis & 8.1 & 8.8 & 9.6 & 10.7 & 11.6 & $10 \mathrm{G}$ \\
\hline
\end{tabular}

${ }^{a}$ Unit of values is $\mathrm{mg} / \mathrm{mL}$.

b Abbreviation: G, Antibiotic disc of gentamicin; P, Antibiotic disc of penicillin.

Table 2. Average Diameter ( $\mathrm{mm}$ ) of Microbial Free Zone Area of Annatto dye Extracted by UAE

\begin{tabular}{lcccccc}
\hline & $\mathbf{0 . 5}^{\mathrm{a}}$ & $\mathbf{1 . 5}^{\mathrm{a}}$ & $\mathbf{2 . 5}^{\mathrm{a}}$ & $\mathbf{3 . 5}^{\mathrm{a}}$ & $\mathbf{5}^{\mathbf{a}^{2}}$ & \multicolumn{2}{c}{ Antibiotic Disk $^{\mathrm{b}}$} \\
\hline Bacillus cereus & 8.7 & 9.9 & 11.6 & 12.6 & 13.3 & $13 \mathrm{P}$ \\
Escherichia coli & 8 & 8.3 & 8.9 & 9.8 & 10.7 & $12 \mathrm{G}$ \\
Staphylococcus aureus & 8.3 & 8.8 & 10.3 & 11.1 & 11.5 & $32 \mathrm{P}$ \\
Salmonella enteritidis & 6.9 & 8.1 & 9 & 10.9 & 11.2 & $10 \mathrm{G}$ \\
\hline Listeria innocua & 8.5 & 9.2 & 10.2 & 11.6 & 12.5 & $22 \mathrm{P}$ \\
Bacillus subtilis & 8.7 & 10.2 & 12.2 & 13.6 & 14.2 & $14 \mathrm{P}$ \\
Streptococcus pyogenes & 8.5 & 9.9 & 11.3 & 12.4 & 13 & $13.5 \mathrm{P}$ \\
Enterococcus faecalis & 8.3 & 9.2 & 9.9 & 11 & 11.8 & $10 \mathrm{G}$ \\
\hline
\end{tabular}

a Unit of values is $\mathrm{mg} / \mathrm{mL}$.

b Abbreviation: G, Antibiotic disc of gentamicin; P, Antibiotic disc of penicillin.

Table 3. MIC of Annatto Dye Extracted By Conventional Method ${ }^{\mathrm{a}, \mathrm{b}}$

\begin{tabular}{|c|c|c|c|c|c|c|c|c|}
\hline & 2 & 4 & 8 & 16 & 32 & 64 & Negative Control & Positive Control \\
\hline Bacillus cereus & + & + & + & - & - & - & - & + \\
\hline Escherichia coli & + & + & + & + & + & - & - & + \\
\hline Staphylococcus aureus & + & + & + & + & - & - & - & + \\
\hline Salmonella enteritidis & + & + & + & + & + & - & - & + \\
\hline Listeria innocua & + & + & + & + & - & - & - & + \\
\hline Bacillus subtilis & + & + & + & - & - & - & - & + \\
\hline Streptococcus pyogenes & + & + & + & + & - & - & - & + \\
\hline Enterococcus faecalis & + & + & + & + & + & - & - & + \\
\hline
\end{tabular}

${ }^{a}$ Unit of values is $\mathrm{mg} / \mathrm{mL}$.

b +, Grow; -, Not grow. 
Yolmeh M et al.

Table 4. MIC of Annatto Dye Extracted by UAE a,b

\begin{tabular}{llllllllc}
\hline & $\mathbf{2}$ & $\mathbf{4}$ & $\mathbf{8}$ & $\mathbf{1 6}$ & $\mathbf{3 2}$ & $\mathbf{6 4}$ & Negative Control & Positive Control \\
\hline Bacillus cereus & + & + & - & - & - & - & - & + \\
Escherichia coli & + & + & + & + & + & - & - & + \\
Staphylococcus aureus & + & + & + & - & - & - & - & + \\
Salmonella enteritidis & + & + & + & + & + & - & - & + \\
Listeria innocua & + & + & + & + & - & - & - & + \\
Bacillus subtilis & + & + & - & - & - & - & - & + \\
Streptococcus pyogenes & + & + & + & - & - & - & - & + \\
Enterococcus faecalis & + & + & + & + & - & - & - & + \\
\hline
\end{tabular}

${ }^{\mathrm{a}}$ Unit of values is $\mathrm{mg} / \mathrm{mL}$.

b +, Grow; -, Not grow.

\begin{tabular}{|c|c|c|c|c|c|}
\hline & 8 & 16 & 32 & 64 & 128 \\
\hline Bacillus cereus & + & - & - & - & - \\
\hline Escherichia coli & + & + & + & + & + \\
\hline Staphylococcus aureus & + & + & + & - & - \\
\hline Salmonella enteritidis & + & + & + & + & + \\
\hline Listeria innocua & + & + & + & - & - \\
\hline Bacillus subtilis & + & - & - & - & - \\
\hline Streptococcus pyogenes & + & + & - & - & - \\
\hline Enterococcus faecalis & + & + & + & - & - \\
\hline
\end{tabular}

${ }^{\mathrm{a}}$ Unit of values is $\mathrm{mg} / \mathrm{mL}$.

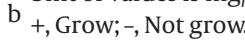

\begin{tabular}{lcccccc}
\hline Table 6. MBC of Annatto Dye Extracted by UAE ${ }^{\mathrm{a}, \mathrm{b}}$ & & & & \\
\hline & $\mathbf{4}$ & $\mathbf{8}$ & $\mathbf{1 6}$ & $\mathbf{3 2}$ & $\mathbf{6 4}$ & $\mathbf{1 2 8}$ \\
\hline Bacillus cereus & + & - & - & - & - & - \\
Escherichia coli & + & + & + & + & + & + \\
Staphylococcus aureus & + & + & + & + & - & - \\
Salmonella enteritidis & + & + & + & + & - & - \\
Listeria innocua & + & + & + & - & - & - \\
Bacillus subtilis & + & - & - & - & - & - \\
Streptococcus pyogenes & + & + & - & + & - \\
Enterococcus faecalis & + & + & + & & - \\
\hline
\end{tabular}

${ }^{\mathrm{a}}$ Unit of values is $\mathrm{mg} / \mathrm{mL}$.

b +, Grow; -, Not grow.

\section{Discussion}

According to the results annatto dye has antibacterial effect and this property decreased by increasing the annatto concentration. Annatto dye extracted by UAE has more antibacterial effect compared to conventional method. So that annatto dyes were extracted by conventional and UAE methods have 13.5 and $14.2 \mathrm{~mm}$ of microbial free zone area in concentration of $5 \mathrm{mg} / \mathrm{mL}$ for $B$. subtilis. The same finding was observed by Thongson et al. evaluate antimicrobial activity of ultrasound-assisted solvent-extracted spices, which observed ultrasound-assisted isopropanol fingerroot extract had more antibacterial activity against Salmonella typhimurium than conventional method 
Yolmeh $M$ et al.

[19]. This phenomenon most likely due to active compounds of annatto dye were damaged in long extraction time of conventional extraction, while UAE method only need a few minutes. The results of MIC assay revealed that annatto dye have more antibacterial effect on Grampositive bacteria compared to Gram-negative bacteria. So that Gram-positive bacteria such as B. cereus and B. subtilis and Gram-negative bacteria such as E. coli and S. enteritidis showed lowest and highest MIC, respectively. The same finding were observed by Galindo-Cuspinera et al, Mohammadi-Sichani et al. and Smith-Palmer et al. for essential oil of Achillea wilhelmsii, annatto extract (2.8\% norbixin), and plant essential oils and essences, respectively $[5,20,21]$. This is probably due to presence of lipopolysaccharide in cell wall of Gram-negative bacteria. Lipopolysaccharides of cell wall can prevent influx of active compounds to cytoplasmic membrane of these bacteria [22]. Annatto dye was extracted by UAE has less MIC for all the bacteria except E. coli, S. enteritidis and L. innocua compared to the dye was extracted by conventional method.

Generally annatto dye has bactericidal effect on was examined the bacteria. B. cereus and B. subtilis showed the lowest MBC for annatto dye extracted by conventional method, whereas this dye has not bactericidal effect on E. coli and S. enteritidis. Galindo-Cuspinera et al. observed also the lowest MIC and MBC of $2.8 \%$ norbixin for B. cere$u s$; in addition they reported that $2.8 \%$ norbixin has not bactericidal effect on S. typhimurium [23]. Tables 5 and 6 depict that annatto dye extracted by UAE has less MBC for the all bacteria except E. coli and L. innocua compared to the dye extracted by conventional method. Moreover, annatto dye extracted by UAE showed a bactericidal effect on S. enteritidis, however the dye extracted by conventional method the opposite is true. IC50 of annatto dye extracted by conventional method was more than annatto dye extracted by UAE. In fact, the antioxidant activity of the annatto dye extracted by UAE is higher than the annatto dye extracted by the conventional method, because carotenoids were damaged in long extraction time of conventional extraction. Our finding is in agreement with other workers such as Oancea et al. They observed that antioxidant activity of anthocyanin extracted from blackberry and sweet cherry cultivar by UAE was more than that of conventional extraction method [24]. Proestos and Komaitis declared aromatic plant extract that extracted by UAE has more total phenolic compounds than the extracted by conventional method [25]. It is important to study scientifically plants that have been used in traditional medicines to determine potential sources of novel antimicrobial compounds [26]. Plant based antimicrobial compounds have enormous therapeutically potential as they can serve the purpose without any side effects that are often associated with synthetic antimicrobials. Plants are employed as important source for traditional medications [27]. In conclusion, annatto dye is a natural and safe colorant to using as food additive. Giving the results the annatto dye extracted by UAE has more antibacterial and antioxidant property compared to conventional method. Annatto dye has more antibacterial effect on Gram-positive bacteria than Gram-negative bacteria. Thus annatto dye addition to make a good appearance in the food can be used as an alternative to synthetic colorants and preservatives.

\section{Acknowledgements}

The present study is retrieved from the thesis code 2123631 in Ferdowsi University of Mashhad, Mashhad, Iran.

\section{Authors' Contributions}

All authors had equal role in design, work, statistical analysis, and manuscript writing.

\section{Funding/Support}

Ferdowsi University of Mashhad, Mashhad, Iran.

\section{References}

1. Babu S, Shenolikar IS. Health \& nutritional implications of food colours. Indian J Med Res. 1995;102:245-9.

2. Sinha K, Chowdhury S, Saha PD, Datta S. Modeling of microwaveassisted extraction of natural dye from seeds of Bixa orellana (Annatto) using response surface methodology (RSM) and artificial neural network (ANN). Ind Crops Prod. 2013;41:165-71.

3. Pattnaik P, Roy U, Jain P. Biocolours: a new generation additives for food. Indian Food Ind. 1997;16(5):21-32.

4. Henry BS. Natural food colours. Glasgow U.K: Blackie Academic and Professional; 1996.

5. Galindo-Cuspinera V, Westhoff DC, Rankin SA. Antimicrobial properties of commercial annatto extracts against selected pathogenic, lactic acid, and spoilage microorganisms. J Food Prot. 2003;66(6):1074-8.

6. Vasu S, Palaniyappan V, Kothandam HP, Badami S. Microwave facilitated extraction of Bixin from Bixa orellana and it's in-vitro antioxidant activity. Der Pharm Lett. 2012;2(2):479-85.

7. Lauro GJ. A primer on natural colors. Cereal Food World. 1991;36:949-53.

8. Siva R, Palackan MG, Maimoon L, Geetha T, Bhakta D, Balamurugan $\mathrm{P}$, et al. Evaluation of antibacterial, antifungal, and antioxidant properties of some food dyes. Food Sci Biotechnol. 2011;20(1):7-13.

9. Tibodeau JD, Isham CR, Bible KC. Annatto constituent cis-bixin has selective antimyeloma effects mediated by oxidative stress and associated with inhibition of thioredoxin and thioredoxin reductase. Antioxid Redox Signal. 2010;13(7):987-97.

10. Wang L, Weller CL. Recent advances in extraction of nutraceuticals from plants. Trends Food Sci Technol. 2006;17(6):300-12.

11. Mandal V, Mohan Y, Hemalatha S. Microwave assisted extraction: an innovative and promising extraction tool for medicinal plant research. Pharmacogn Rev. 2007;1(1):7-18.

12. Natarajan V, Venugopal PV, Menon T. Effect of Azadirachta indica (neem) on the growth pattern of dermatophytes. Indian J Med Microbiol. 2003;21(2):98-101.

13. Rojas JJ, Ochoa VJ, Ocampo SA, Munoz JF. Screening for antimicrobial activity of ten medicinal plants used in Colombian folkloric medicine: a possible alternative in the treatment of non-nosocomial infections. BMC Complement Altern Med. 2006;6:2.

14. Lewis K, Ausubel FM. Prospects for plant-derived antibacterials. Nat Biotechnol. 2006;24(12):1504-7.

15. Castello M, Chandra N, Phatak A, Sharon M. Estimation of bixin in seeds of Bixa orellana L. from different locations in western Maharashtra. Indian J Plant Physiol. 2004;9(2):185-8.

16. Yolmeh M, Habibi Najafi MB, Farhoosh R. Optimisation of ultrasound-assisted extraction of natural pigment from annatto seeds by response surface methodology (RSM). Food Chem. 2014;155:319-24. 
17. Manenzhe NJ, Potgieter N, van Ree T. Composition and antimicrobial activities of volatile components of Lippia javanica. Phytochem. 2004;65(16):2333-6.

18. Kurniawati PT, Soetjipto H, Limantara L. Antioxidant and antibacterial activities of Bixin pigment from Annatto (Bixa orellana L.) seeds. Indo J Chem. 2007;7(1):88-92.

19. Thongson C, Davidson PM, Mahakarnchanakul W, Weiss J. Antimicrobial activity of ultrasound-assisted solvent-extracted spices. Lett Appl Microbiol. 2004;39(5):401-6.

20. Mohammadi-Sichani M, Amjad L, Mohammadi-Kamalabadi M. [Antibacterial activity of methanol extract and essential oil of Achillea wilhelmsii against pathogenic bacteria]. persian. Zahedan J Res Med Sci. 2011;13(3):14-9.

21. Smith-Palmer A, Stewart J, Fyfe L. Antimicrobial properties of plant essential oils and essences against five important foodborne pathogens. Lett Food Microbiol.1998;26(2):118-22.

22. McKeegan KS, Borges-Walmsley MI, Walmsley AR. Microbial and viral drug resistance mechanisms. Trends Microbiol. 2002;10(10 Suppl):S8-14.

23. Galindo Cuspinera V . [Volatile composition and antimicrobia properties of commercial annatto (Bixa orellana L) extracts, a natural food colorant]. USA: University of Maryland; 2003.

24. Oancea S, Grosu C, Ketney O, Stoia M. Conventional and ultrasound-assisted extraction of anthocyanins from blackberry and sweet cherry cultivars. Acta Chim Slov. 2013;60(2):383-9.

25. Proestos C, Komaitis M. Ultrasonically assisted extraction of phenolic compounds from aromatic plants: comparison with conventional extraction technics. J Food Qual.2006;29(5):567-82.

26. Hammer KA, Carson CF, Riley TV. Antimicrobial activity of essential oils and other plant extracts. J Appl Microbiol. 1999;86(6):985-90.

27. Neves JM, Matos C, Moutinho C, Queiroz G, Gomes LR. Ethnopharmacological notes about ancient uses of medicinal plants in Tras-os-Montes (northern of Portugal). J Ethnopharmacol. 2009;124(2):270-83. 